\title{
An open label pilot trial of Abhaya Ghrita in autistic disorder
}

\begin{abstract}
Autism is a developmental disorder characterized by impaired social interaction, communication, repetitive behaviors and restricted interests. Autism spectrum disorders (ASD) is a clinically defined behavioral syndrome that manifests in early childhood. In India prevalence rate of ASD is $1.2 \%$. There is a little evidence of any 'cure' for Autism. There is lack of sufficient data regarding Ayurvedic strategy of managing this condition. The present study was aimed to assess the efficacy of "Abhaya ghrita", which contains Brahmi (Bacopa monnieri), Kushta (Saussurea lappa Clarke), Vacha (Acorus calamus Linn), Pippali (Piper longum Linn) etc herbs. In present study, 10 patients with 'Autistic disorder', satisfying the DSM-IV-TR (Diagnostic and statistical manual for mental disorders) diagnostic criteria were selected. Abhaya ghrita (with a dose of 5-10ml) has been given orally twice a day for three months. Total three assessments were taken, before starting treatment, after completion of treatment and after follow up. Criteria of assessment were based on the scoring of 'Indian scale for assessment of Autism (ISAA). Paired ' $t$ ' test was used for statistical evaluation. Abhaya ghrita has provided $10.69 \%$ of relief on ISAA, which was considered as clinically unsatisfactory.
\end{abstract}

Keywords: autistic disorder, autism, autism spectrum disorders, ayurveda, abhaya ghrita, indian scale for assessment of autism
Volume II Issue 3 - 2018

\author{
Bharati Patil,' Prasad Mamidi,' Sunil Changle \\ 'Department of Kaumarabhritya, Parul University, India \\ ${ }^{2}$ Principal, SAM College of Ayurvedic sciences \& Hospital, SAM \\ Group of Institutions, India
}

\begin{abstract}
Correspondence: Prasad Mamidi,Associate Professor, Dept of Kayachikitsa, Parul Institute of Ayurved, Parul University, Vadodara, Gujarat, India, Tel 7567222856, Email drprasadmamidi@gmail.com
\end{abstract}

Received: April 20, 2018 | Published: May II, 2018

\section{Introduction}

Autism is a developmental disorder which is characterized by impaired social communication, interaction, stereotypic behaviors and restricted interests. Signs and symptoms of Autism are still unclear. ${ }^{1}$ Autism spectrum disorders (ASD) is a syndrome which manifests during early childhood. The characteristic features of ASD include abnormal or unreciprocated interpersonal \& emotional interactions, disturbed language \& communication, and repetitive \& stereotypic behavior. ${ }^{2}$ Global prevalence of ASD ranges from $0.07 \%$ to $1.8 \%$. In India prevalence rate of ASD is $1.2 \%$. Male gender and upper socio economic status had a higher risk of Autism. ${ }^{3}$ There is a little evidence of any 'cure' for Autism. ${ }^{4}$ Parents of autistic children mostly prefer alternative therapies for improving developmental progression in language skills and social interactions. People often turn to 'Complementary and alternative medicine' (CAM) when they have a chronic problem that conventional medicine hasn't cured. Certain treatments, diets, behavioral therapies, herbal remedies have shown promising effects on autism patients. ${ }^{5}$

Description regarding Autism is not available in the classical texts of Ayurveda, only scattered information about Autism like conditions is available. ${ }^{6}$ Autism and other disorders with autistic features fall under the category of 'Unmada' (psychosis). Unmada is characterized by the impairment of Manas (mind), Buddhi (cognitive functions), Samgna gnana (perception), Bhakti (desire/interests), Sheela (character / personality), Cheshta (motor activities) and Achara (conduct). ${ }^{7}$ Although outcome for adults with autism has improved, many of them remain highly dependent on others for support. Majority of the children treated for Autism have shown 'poor' (46\%) and 'very poor' $(12 \%)$ outcome. $^{8}$

In present study, "Abhaya ghrita" was selected for treating Autistic disorder (AD). This formulation has been mentioned in 'Kashyapa samhita" and 'Ashtanga hridaya'. ${ }^{10}$ Abhaya ghrita contains six herbs,
Brahmi (Bacopa monnieri), Siddharthaka (Brassica compestris), Kushta (Saussurea lappa Clarke), Vacha (Acorus calamus Linn), Sariva (Hemidesmus indicus), Pippali (Piper longum Linn) and Saindhava lavana (salt). Abhaya ghrita improves speech, vocabulary, language, cognitive functions, memory, intelligence and vision. ${ }^{9,10}$

\section{Materials and methods}

\section{Aim \& objective}

To evaluate the efficacy of 'Abhaya ghrita' in the management of $\mathrm{AD}$.

\section{Study design}

An open label pilot study

\section{Selection of subjects}

Total 10 subjects were recruited by following simple random sampling from the OPD (out-patient department) of 'Parul Ayurveda hospital'.

\section{Inclusion criteria}

Subjects who have fulfilled the 'DSM-IV TR' (Diagnostic and statistical manual of mental disorders, $4^{\text {th }}$ edition, text revision) diagnostic criteria of 'Autistic disorder' $(299.00)^{11}$ were included in the present study. Subjects belongs to the age group 5-12 years were only included.

\section{Exclusion criteria}

Subjects who had history of head injury, major systemic illness and who have been taking psychotropic medicines were excluded in the present study. Children who suffered with any other major neurological or psychiatric pathology were also excluded. 


\section{Laboratory investigations}

Hematological, biochemical and radiological investigations have been carried out according to the necessity to exclude organic pathology in suspected cases only. If any abnormalities found in investigation reports those patients were excluded from the study. In present study no patient is excluded in such a manner.

\section{Ethical clearance}

Ethical clearance was obtained from 'Institutional Ethics Committee (IEC)' of Parul Institute of Ayurveda, Parul University (vide ref-PIA/IECHR/2015-16/KB/010 dated 22/10/2016).

\section{Registration}

This study is registered in 'Clinical Trial Registry of India (CTRI)' (vide CTRI/2017/05/008454).

\section{Informed consent}

An informed written consent was obtained from the parents or guardians of children. The consent form was prepared in accordance with the guidelines of 'World health organization' (WHO)-Research Ethics Review Committee (ERC). The informed consent form used in the present study has two parts: Patient information sheet (included subjects receive a copy) and a certificate of consent (signed by the parents or care taker).

\section{Assessment criteria}

Total three assessments were taken, before treatment $\left(1^{\text {st }}\right.$ day), after treatment ( $90^{\text {th }}$ day) and after follow up (120 $0^{\text {th }}$ day) by using the 'Indian scale for assessment of Autism' (ISAA). ISAA is an objective assessment tool for person with autism and it consists of 40 items rated on 5 point scale ranging from 1 (never) to 5 (always). The 40 items of ISAA are divided under six domains, 'social relationship and reciprocity', 'emotional responsiveness', 'speech, language and communication', 'behavioral patterns', 'sensory aspects' and 'cognitive component'. ISAA score less than 70 is considered as 'normal', 70-106 (mild autism), 107-153 (moderate autism) and score of above 153 is considered as 'severe autism'. ${ }^{12}$

\section{Intervention}

Abhaya ghrita was prescribed with the dose of 5-10ml (exact dose was calculated by using 'Young's rule), twice a day, orally before food for the period of 90 days. Follow up period was kept for 30days after completion of the treatment period.

\section{Statistical analysis}

Statistical analysis was done by using "student's paired t-test". Raw data was subjected to statistical analysis in terms of mean difference, standard deviation, standard error, paired ' $t$ ' test etc. Statistically significance level was kept at, $\mathrm{p}<0.05$.

\section{Observations}

In present study total 10 subjects $(n=10)$ were recruited and all of them successfully completed the protocol. In present study, $80 \%$ subjects were female, $70 \%$ subjects belongs to $9-12 \mathrm{yrs}$ of age group, all subjects belongs to 'Hindu' religion, $60 \%$ were from above poverty line, $80 \%$ subjects were from rural area, $60 \%$ subjects were from joint family and $90 \%$ of parents of the subjects were educated up to higher secondary. Present study showed that $60 \%$ parents of the subjects were 'supportive' and have shown 'positive parenting attitude' towards Autistic child. Among parents of Autistic children, $40 \%$ were 'over protective', $40 \%$ were 'lax in discipline', $10 \%$ were 'abusive' and $40 \%$ of the parents had alcohol addiction. Out of 10 subjects, $40 \%$ of the subjects had shown positive family history for AD and almost all the subjects were suffering from delayed developmental milestones. Only $30 \%$ of the subjects were going to Special school.

Out of 10 subjects, $40 \%$ of mothers of the AD children had positive ante-natal birth history like anemia, fever, preeclampsia and $40 \%$ had positive post-natal history like lower segment cesarean section (LSCS), fetal distress and low birth weight. Almost all the subjects have shown impaired peer relation and learning disorder; only $20 \%$ of the subjects were actively participated in school activities, $30 \%$ of $\mathrm{AD}$ children have shown special interest in singing, drawing etc. Rigid, stereotypic behavior and fixed food habits were found in $60 \%$ of the subjects. Present study has shown that almost all the subjects were suffering from impaired social interaction, impairment in communication and impaired peer relation.

\section{Results}

Maximum relief, i.e. 16\% $(\mathrm{P}<0.005)$ found in 'remains aloof' feature which belongs to the 'social relationship and reciprocity' domain. In 'emotional responsiveness' domain maximum relief, i.e. $13.7 \%(\mathrm{P}<0.03)$ was found in 'shows inappropriate emotional response' feature. In 'speech-language and communication' domain maximum relief, i.e. $19.4 \%(\mathrm{P}<0.03)$ was found in 'echolalic speech'. In 'behavioral patterns' domain, maximum relief, i.e. $16.1 \%(\mathrm{P}<0.01)$ was found in 'insists on sameness' feature. In 'sensory aspect' $\&$ 'cognitive components' domain, maximum relief, i.e. $18.1 \%$ $(\mathrm{P}<0.005)$ was found in 'show delay in responding' feature.

Maximum relief, i.e. $13.08 \%(\mathrm{P}<0.001)$ found in 'sensory aspects' and 'cognitive components' of ISAA followed by 'emotional responsiveness' $10.52 \% \quad(\mathrm{P}<0.013)$ and 'social relationship \& reciprocity' $9.35 \%(\mathrm{P}<0.001)$ (Table 1$)$. Similar findings were observed after completion of follow up period also (Table 1). Overall relief on total score of ISAA after treatment was $10.69 \%(\mathrm{P}<0.001)$ and after follow up also similar findings were observed (Table 2). Overall effect of therapy based on ISAA scoring has revealed that only in $20 \%$ of the subjects mild improvement (25-50\% of score reduction in ISAA) was found. Maximum number of the subjects $(80 \%)$ didn't get satisfactory relief $(<25 \%$ of score reduction in ISAA).

\section{Discussion}

ASD is a spectrum which includes profound mental retardation and impaired speech as well as communication. ASD is a neurodevelopmental syndrome characterized by deficits in social reciprocity \& communication, and by abnormal, restricted \& stereotypic behaviors. ${ }^{12}$ Most of the children with Autism have remained highly dependent on their families or other support services during adulthood. Impaired communication, poor reading, spelling abilities and stereotyped behaviors or rigid interests frequently persisted into adulthood. ${ }^{8}$ Autism can be managed effectively through the rational utility of certain Ayurvedic drugs and procedures. ' Abhaya ghrita' is mentioned in 'Lehyadhyaya' of 'Kashyapa samhita' and 'Baalopacharniya adhyaya' of 'Ashtanga hridaya'. ${ }^{9,10}$ It is indicated for improving various cognitive functions, memory, intelligence, speech and language skills, and vocabulary. Based on these reasons Abhaya ghrita was selected to treat Autism in present study. 
Abhaya ghrita contains various herbs which are well documented for treating various psychiatric conditions. Kushta has the properties like, vedanasthapana (analgesic), rakshoghna (protective/enhancing immunity), vajikarana (tonic/aphrodisiac), avasada hara (antidepressant) and aksheepashamaka (anti-convulsant); it has been found useful in treating various psychosomatic disorders. Vacha has shown the properties like, medhya (intellect promoting), shamaka (depressant), vedanasthapana and akshepashamana. It is used as a sedative, anxiolytic, tranquilizer and rejuvenator. Vacha is also used to reduce fatigue and to improve memory. Vacha has memory enhancing and behavior modifying properties. Vacha also improves learning performance. ${ }^{13}$ Brahmi has shown properties like, anxiolytic, antidepressant, muscle relaxant, anti stress adaptogen, medhya rasayana (neutraceutical) and unmada hara (anti psychotic). Pippali is having deepana (stomachic) and paachana (diegestant) properties which improves the drug absorption and bioavailability. ${ }^{14}$ In present study Abhaya ghrita has not provided satisfactory relief. After treatment period on total score of ISAA, only $10.69 \%$ relief $(\mathrm{P}<0.001)$ was observed.

\section{Reasons for limited efficacy}

Duration of treatment in the present study was three months. Previous studies on Ayurvedic management of Autism have suggested long term intervention. ${ }^{6}$ We suggest that future studies should consider longer duration (more than 3months). The prognosis of Autism for everyday life adaptation is extremely variable. ${ }^{1}$ Individuals with Autism, who has shown childhood performance IQ (intelligence quotient) of at least 70 had a significantly better outcome than those with an IQ level below this. IQ proved to be consistent prognostic indicator in Autism. ${ }^{8}$ In present study all the patients $(100 \%)$ had history of delayed milestones, which may be one of the causes for poor outcome. Treatment in the early years can play a significant role in enhancing functioning in later life in Autism children. ${ }^{4}$ Most of the subjects $(70 \%)$ in present study belong to $9-12$ years age group which indicates chronicity of the condition and also late intervention. Chronicity and late intervention might be the underlying factors for poor outcome in present study. By considering the above facts it seems that, shorter duration of treatment, low IQ and/or delayed milestones, chronicity, late intervention, comorbid conditions and lack of special education etc factors all together might have influenced the outcome in present study.

\section{Conclusion}

'Abhaya ghrita' has shown limited efficacy in the management of 'Autistic disorder'.

\section{Acknowledgments}

None.

\section{Conflict of interest}

Author declares there is no conflict of interest.

\section{References}

1. Hill EL, Frith U. Understanding autism:insights from mind and brain. Philos Trans R Soc Lond B Biol Sci. 2003;358(1430):281-289.

2. Raina SK, Kashyap V, Bhardwaj AK, et al. Prevalence of autism spectrum disorders among children (1-10 years of age) - Findings of a mid-term report from North west India. J Postgrad Med. 2015;61(4):243-246.

3. Anirudhan R, Nalinakshan A. Effect of Brahmisohaladi sirolepa in children with Autism spectrum disorders. International Journal of Ayurveda and Pharma Research. 2017;5(12):9-45.

4. Howlin P. Prognosis in autism:do specialist treatments affect long-term outcome? Eur Child Adolesc Psychiatry. 1997;6(2):55-72.

5. Ghosh S, Koch M, Suresh Kumar V, et al. Do Alternative Therapies Have a Role in Autism? Online J Health Allied Scs. 2009;8(4):2.

6. Patil PL, Bonde PW. An overview and approach towards Autism and its management in Ayurveda. Ped Health Res. 2018;3(1):1.

7. Sandip kumar RS, Musale SV, Pradip kumar SR. Childhood AutismAn Ayurvedic approach. International Journal of Applied Ayurveda Research. 2015;2(1):1-8.

8. Howlin P, Goode S, Hutton J, et al. Adult outcome for children with Autism. J Child Pyschol Psychiatry. 2004;45(2):212-229.

9. Vriddha Jivaka, Kashyapa samhita, Sutra sthana. Lehadhyaya - 1/16, translated by Namani Krishnaiah. $1^{\text {st }}$ ed. Tirupati: Shri Siddhartha publications; 2000. p. 6.

10. Vagbhata, Ashtanga Hridaya. Commentary by Arunadatta and Hemadri, Uttara tantra, Balopacharaneeya adhyaya, 1/42. edited by Bhishagacharya Harishastri Paradkara Vaidya. $9^{\text {th }}$ ed. Varanasi: Chowkhamba Sanskrit series office; 2005. p. 791.

11. American Psychiatric Association. Diagnostic and Statistical Manual of Mental Disorders-Text Revision (DSM-IV-TR). Disorders usually first diagnosed in infancy, childhood, or adolescence - Autistic disorder (299.00). $4^{\text {th }}$ ed. New Delhi: Jaypee Publications; 2000. p. 70-75.

12. http://wcdsc.ap.nic.in/documents/autism.pdf.

13. Prasad Mamidi, Kshama Gupta. Efficacy of Aadhi nashaka choorna (Ayurvedic compound formulation) in Obsessive Compulsive Disorder:An open trial. Int Res J Pharm. 2015;6(12):828-831.

14. Gupta K, Mamidi P, Thakar AB. Randomized placebo controlled study on Sarasvata choorna in generalized anxiety disorder. Int $J$ Green Pharm. 2014;8:231-6. 